\title{
A surgical case of lung cancer with poor general status associated with parathyroid hormone-related protein
}

\author{
Toshiko Kamata ${ }^{1}$, Eitetsu Koh ${ }^{1}$, Atsuko Masunaga ${ }^{2}$, Asako Okabayashi ${ }^{3}$, Mizue Hasegawa $^{3}$, Hideki \\ Katsura $^{3}$, Kenzo Hiroshima ${ }^{2}$, Yasuo Sekine ${ }^{1}$ \\ ${ }^{1}$ Department of Thoracic Surgery, ${ }^{2}$ Department of Pathology, ${ }^{3}$ Department of Respiratory Medicine, Tokyo Women's Medical University, Yachiyo \\ Medical Center, Yachiyo-shi, Chiba, Japan \\ Correspondence to: Toshiko Kamata. Department of Thoracic Surgery, Tokyo Women's Medical University, Yachiyo Medical Center, 477-96 \\ Ohwadashinden, Yachiyo-shi, Chiba 276-8524, Japan. Email: tkamata-cib@umin.ac.jp.
}

\begin{abstract}
Parathyroid hormone-related protein (PTHrP), which is released in the presence of malignant disease, is associated with hypercalcemia. Complete resection of the tumor in such patients is rarely performed because of their poor general condition. We herein report a case of lung cancer associated with PTHrP in a patient whose condition dramatically improved after surgery. We also review the literature on the benefits of various surgical options. Although only a few cases of complete resection in such patients have been reported, the mental and physical condition of the patients improved postoperatively and the median survival time was longer than 12 months. A poor general status is frequently considered a contraindication for surgery, even in a palliative setting; however, we conclude that resection of lung cancer may lead to improved symptom control and survival when the patient's condition is induced by hypercalcemia secondary to PTHrP secretion from the tumor.
\end{abstract}

Keywords: Lung cancer; parathyroid hormone-related protein (PTHrP); humoral hypercalcemia of malignancy (HHM); surgery

Submitted Dec 30, 2017. Accepted for publication Apr 08, 2018.

doi: $10.21037 /$ jtd.2018.04.96

View this article at: http://dx.doi.org/10.21037/jtd.2018.04.96

\section{Introduction}

Paraneoplastic syndromes are frequently caused by ectopic hormone production. Common manifestations are hypercalcemia [humoral hypercalcemia of malignancy (HHM)] caused by Parathyroid hormone-related protein (PTHrP), hyponatremia from excess vasopressin, and Cushing's syndrome from ectopic adrenocorticotropic hormone secretion (1). Squamous cell carcinoma is the most frequent type of PTHrP-producing lung cancer $(2,3)$. Tumor progression is usually rapid in patients with HHM (4). In the normal state, the serum calcium level is regulated by parathyroid hormone $(\mathrm{PTH})$, vitamin $\mathrm{D}$, and calcitonin. PTH activates vitamin $\mathrm{D}$, stimulates calcium reabsorption from the nephron, and leads to calcium mobilization from the bone. PTHrP is very similar to PTH and acts on bone and kidney, leading to hypercalcemia (5). Hypercalcemia induces circulatory, neurological, and gastrointestinal effects (6). Resection of the tumor is rarely performed because of the patient's poor condition. We herein report a case of lung cancer associated with high PTHrP levels. The patient's general condition dramatically improved after complete resection of the tumor. We also review the literature, focusing on the feasibility of surgical resection in PTHrP-associated lung cancer.

\section{Case presentation}

A 73-year-old man complaining of general malaise was admitted to a private hospital with hypercalcemia and extensive infiltrating shadows in his left lung. His medical history was unremarkable and he had a smoking history of 75 pack-years. The lung lesions were resistant to antibiotic therapy and his tumor markers [carcinoembryonic antigen 
Table 1 Blood analysis results on admission

\begin{tabular}{lc}
\hline Laboratory data & Results \\
\hline Blood chemistry & \\
Total protein & $6.8 \mathrm{~g} / \mathrm{dL}$ \\
Albumin & $2.5 \mathrm{~g} / \mathrm{dL}$ \\
Lactate dehydrogenase & $393 \mathrm{U} / \mathrm{L}$ \\
Blood urea nitrogen & $11 \mathrm{~g} / \mathrm{dL}$ \\
Creatinin & $0.51 \mathrm{mg} / \mathrm{dL}$ \\
Calcium & $11.4 \mathrm{mg} / \mathrm{dL}$ \\
Inorganic phosphorus & $2.6 \mathrm{mg} / \mathrm{dL}$ \\
Tumor markers & \\
CEA & $7,353.1 \mathrm{ng} / \mathrm{mL}$ \\
CYFRA & $184 \mathrm{ng} / \mathrm{mL}$ \\
intact PTH & $7.0 \mathrm{pg} / \mathrm{mL}$ \\
intact PTHrP & $29.7 \mathrm{pmol} / \mathrm{L}$ \\
TNF alpha & $4.43 \mathrm{pg} / \mathrm{mL}$ \\
IL-6 & $2.6 \mathrm{mg} / \mathrm{dL}$ \\
\hline
\end{tabular}

(CEA) and cytokeratin-19 fragment (CYFRA)] were elevated. He was transferred to our hospital for further evaluation.

The patient exhibited generalized wasting and delirium on admission. He had severe appetite loss and required assistance in eating. He had a productive cough and his muscle strength was reduced, leading to difficulty in standing. The patient also had bladder incontinence and multiple dental caries. His height was $166.2 \mathrm{~cm}$, weight was $44.1 \mathrm{~kg}$, and body mass index (BMI) was $16.0 \mathrm{~kg} / \mathrm{m}^{2}$. His body temperature was $36.7^{\circ} \mathrm{C}$, blood pressure was $113 / 64 \mathrm{mmHg}$, heart rate was 76 beats $/ \mathrm{min}$, and $\mathrm{SpO}_{2}$ was 95-99\% with oxygen inhalation at $3 \mathrm{~L} / \mathrm{min}$.

Blood analysis (Table 1) showed hypoalbuminemia, moderate hypercalcemia (calcium $11.4 \mathrm{mg} / \mathrm{dL}$; adjusted value $12.9 \mathrm{mg} / \mathrm{dL}$ ), and elevated tumor markers (CEA, 7,353.1 ng/mL; CYFRA, $184 \mathrm{ng} / \mathrm{mL})$. The intact PTH level was low at $7.0 \mathrm{pg} / \mathrm{mL}$, and the intact PTHrP level was high at $29.7 \mathrm{pmol} / \mathrm{L}$.

Chest X-ray findings showed infiltration in the left lower lung field (Figure 1A). Chest computed tomography showed a large lesion occupying most of the left lower lobe (Figure 1B). Fluorodeoxyglucose-positron emission tomography (FDG-PET) showed high intake in the mass shadow. Transbronchial lung tissue biopsy with bronchoscopy from
B8, B9, and B10 showed non-small cell lung cancer. The clinical stage was cT4N0M0 stage IIIA.

Treatment for hypercalcemia was initiated with a bisphosphonate (zoledronic acid), which was administered twice in 10 days with fluid replacement. Nutritional support was initiated, with high-calorie supplements added to each meal. His oral intake increased from 400 to 600 $800 \mathrm{kcal} /$ day. An additional $420 \mathrm{kcal}$ was applied by peripheral intravenous nutrition. Bronchial toileting and dental care were performed. The psychological evaluation excluded dementia. A physical therapist intervened in daily exercises. Although the patient was initially uncooperative with these treatments, he became less delirious and his muscular strength improved to some extent, enabling standing. His cough resolved within 2 weeks.

Because the patient's poor mental and physical status was thought to be the result of humoral factors, surgical resection of the tumor was considered. Surgery was performed through a posterior lateral thoracotomy. Left lower lobectomy and lymph node dissection were performed. More than $90 \%$ of the left lower lobe was replaced by the tumor, with extensive discoloration of the lung surface (Figure 1C). Because of the large tumor size, the interlobar pleura was dissected first; the pulmonary artery was then resected, followed by the lower lobe bronchus. Finally, the inferior pulmonary vein was resected. The histological diagnosis was moderately to poorly differentiated squamous cell carcinoma (p-T4N0M0pl0pm1ly0v0 stage IIIA; UICC version 8). The tumor was $160 \mathrm{~mm}$ in size with no pleural invasion (Figure 1D). Additional immunohistochemical analysis showed that the tumor was positive for PTHrP anti PTHrP [1-34]-NH2 serum, Y201; Yanaihara Institute, Shizuoka, Japan\} (Figure 1E).

The serum PTHrP level decreased to $10 \mathrm{pmol} / \mathrm{L}$ postoperatively, and the serum calcium level rapidly decreased to $8.6 \mathrm{mg} / \mathrm{dL}$ (adjusted calcium, $10.7 \mathrm{mg} / \mathrm{dL}$ ) at 3 days postoperatively and to $7.7 \mathrm{mg} / \mathrm{dL}$ (adjusted calcium, $9.7 \mathrm{mg} / \mathrm{dL}$ ) at 9 days postoperatively (Figure 2). The patient's oral intake gradually increased to $1,000-1,200 \mathrm{kcal} /$ day and his incontinence resolved. His mental status and activity improved, and he was discharged on the 11th postoperative day. His serum PTHrP level normalized in the third week following the operation and his CEA level decreased to $141.8 \mathrm{ng} / \mathrm{mL}$ at 3 months of follow-up. The patient remained as an outpatient for 6 months and his lung cancer then recurred. His CEA value increased to $655 \mathrm{ng} / \mathrm{mL}$ and multiple lung nodules were detected on FDG-PET. 

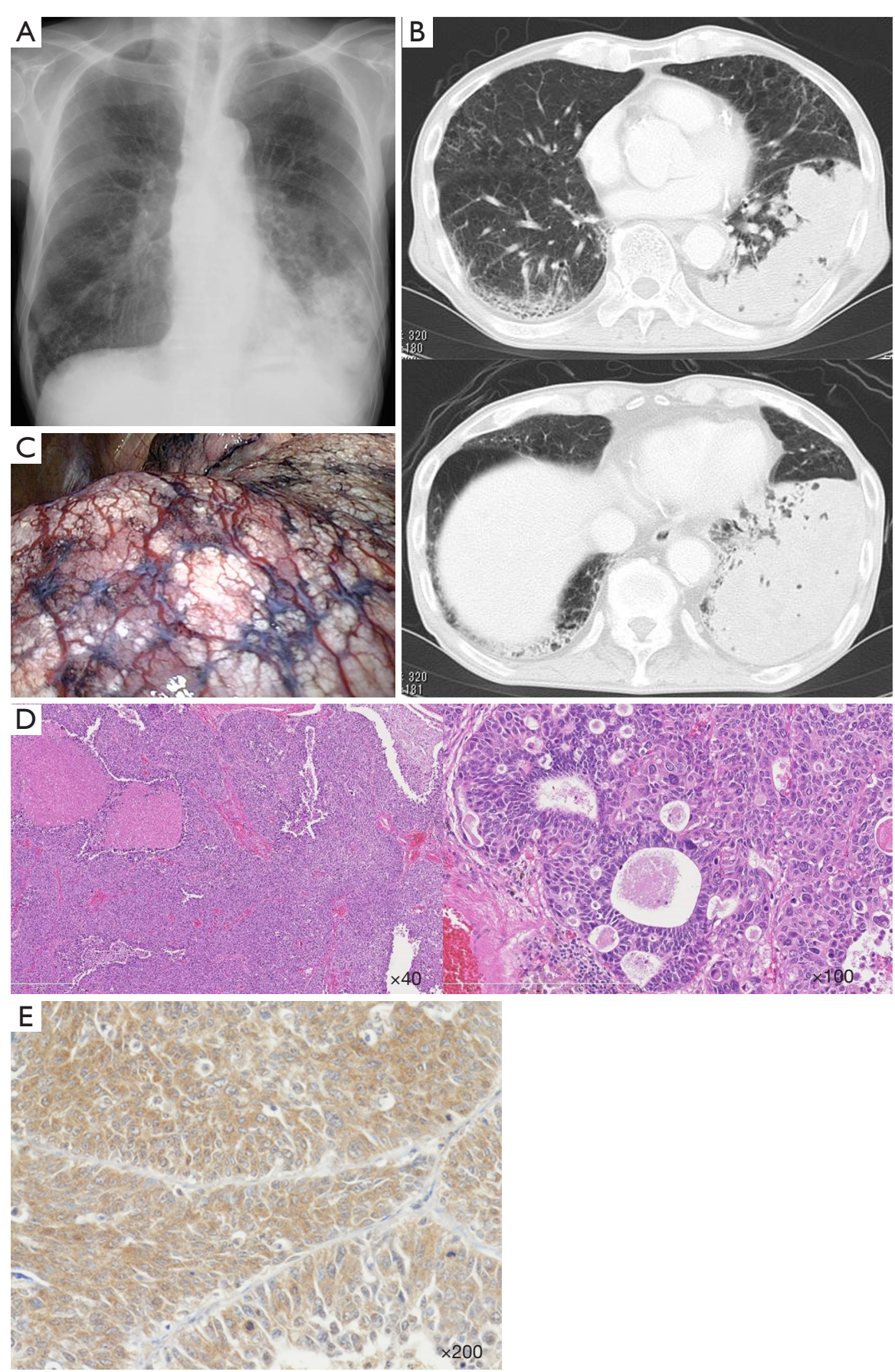

Figure 1 Clinical, surgical and pathological findings. (A) An infiltrating shadow in the left lower lung field can be seen on a chest radiograph; (B) a large mass shadow occupies most of the left lower lobe on chest computed tomography; (C) the left lower lobe is distended with the tumor, and vast discoloration can be seen. More than $90 \%$ of the lobe is replaced by the tumor; (D) the histological diagnosis is moderately to poorly differentiated squamous cell carcinoma; (E) immunohistochemical staining for PTHrP is positive in the resected tumor. 


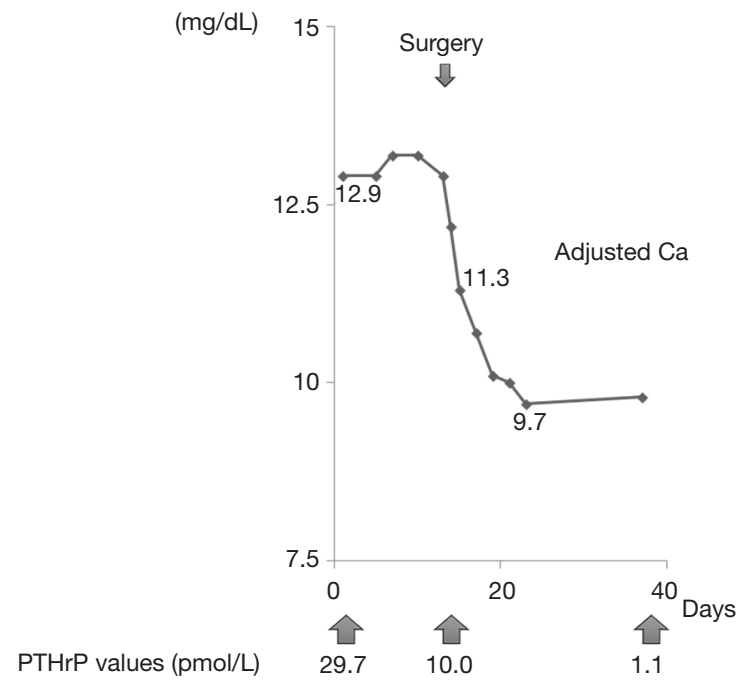

Figure 2 Perioperative changes in serum calcium and PTHrP values. These values were remarkably reduced postoperatively.

His serum calcium level was $10.4 \mathrm{mg} / \mathrm{dL}$ at this point, but gradually increased during the following 4 months to $14.3 \mathrm{mg} / \mathrm{dL}$ (adjusted for serum albumin). He could tolerate chemotherapy because his general condition had improved. He was alive with recurrent disease at the time of this writing (9 months postoperatively).

\section{Discussion}

Radical resection of lung cancer associated with hypercalcemia is rarely reported. Hypercalcemia is frequently induced by bone metastases, but in some patients, it is caused by HHM (7). Several authors have described a PTHlike substance associated with hypercalcemia in patients with malignancy, and this substance resolved after lung resection (8,9). In 1987, Suva et al. isolated PTHrP from the medium of a squamous cell lung cancer cell line (10).

Hypercalcemia in patients with cancer suggests an advanced stage and poor survival, with a median survival of 1 month from diagnosis (3). PTHrP possesses transforming growth factor-like activities, causing rapid progression of the disease (11).

Because only a few reports have described surgical resection, we reviewed the English and Japanese literature to examine the possible benefits of surgery on PTHrPreleasing lung cancer (Table 2). Thirteen cases including the present case, were identified. The serum PTHrP level was not directly measured in 5 of these 13 cases. These cases were included as probable PTHrP-associated cases because extensive analysis of blood and urinary samples showed that a PTH-like substance was secreted by tumor cells. The mean age of the patients was 63.8 years, and 11 were male. The mean tumor size was $96.3 \mathrm{~mm}$ (data were available in 8 patients), and 11 of 13 (84.6\%) tumors had squamous cell histology. Extended resections, such as sleeve lobectomy, pneumonectomy, or bilobectomy, were frequently performed $(\mathrm{n}=5,38.5 \%)$. The preoperative serum calcium levels were elevated in all patients, ranging from 12.1 to $16.4 \mathrm{mg} / \mathrm{dL}$ (mean, $14.1 \mathrm{mg} / \mathrm{dL}$ ). Impairment of consciousness, such as delirium, was found in 6 patients; muscle weakness in 5; and a poor nutritional status in 10 . The BMI was available in eight patients, and the average BMI was $17.4 \mathrm{~kg} / \mathrm{m}^{2}$. In six patients, calcitonin or bisphosphonate was administered preoperatively to reduce the serum calcium level. The serum calcium level rapidly normalized following surgery, with improvement of the patient's appetite and mental and physical status. Three patients experienced transient hypocalcemia in the early postoperative phase, but only one patient required calcium infusion. Five patients had died of lung cancer at the time of the report. The median survival was not reached in the 13 patients.

These findings indicate that, although a poor cognitive and physical status makes lung cancer surgery more difficult, patients with HHM may benefit from tumor resection. Treatment of hypercalcemia with hydration and administration of calcitonin, bisphosphonate or denosumab (5) is recommended prior to surgery. This may stabilize the patient's condition and help in determining which patients may benefit from tumor resection. Careful monitoring of serum calcium in the perioperative phase is also required in these patients. Because patients with HHM have a low expectancy of long-term survival, surgery in these patients may be considered palliative. Palliative surgery is performed for symptom relief, such as control of pain or hemorrhage and stabilization of the musculoskeletal system $(12,13)$. However, such surgery is also associated with significant morbidity and mortality. Miner et al. concluded that symptom resolution can be anticipated in $80-90 \%$ of carefully selected patients, while a poor performance status, poor nutritional status, and weight loss are reportedly associated with diminished survival and may be contraindications $(13,14)$. Patients with HHM are frequently malnourished and have a poor performance status, so one might conclude that they are poor candidates for palliative surgery. According to our review, however, the median survival of patients 


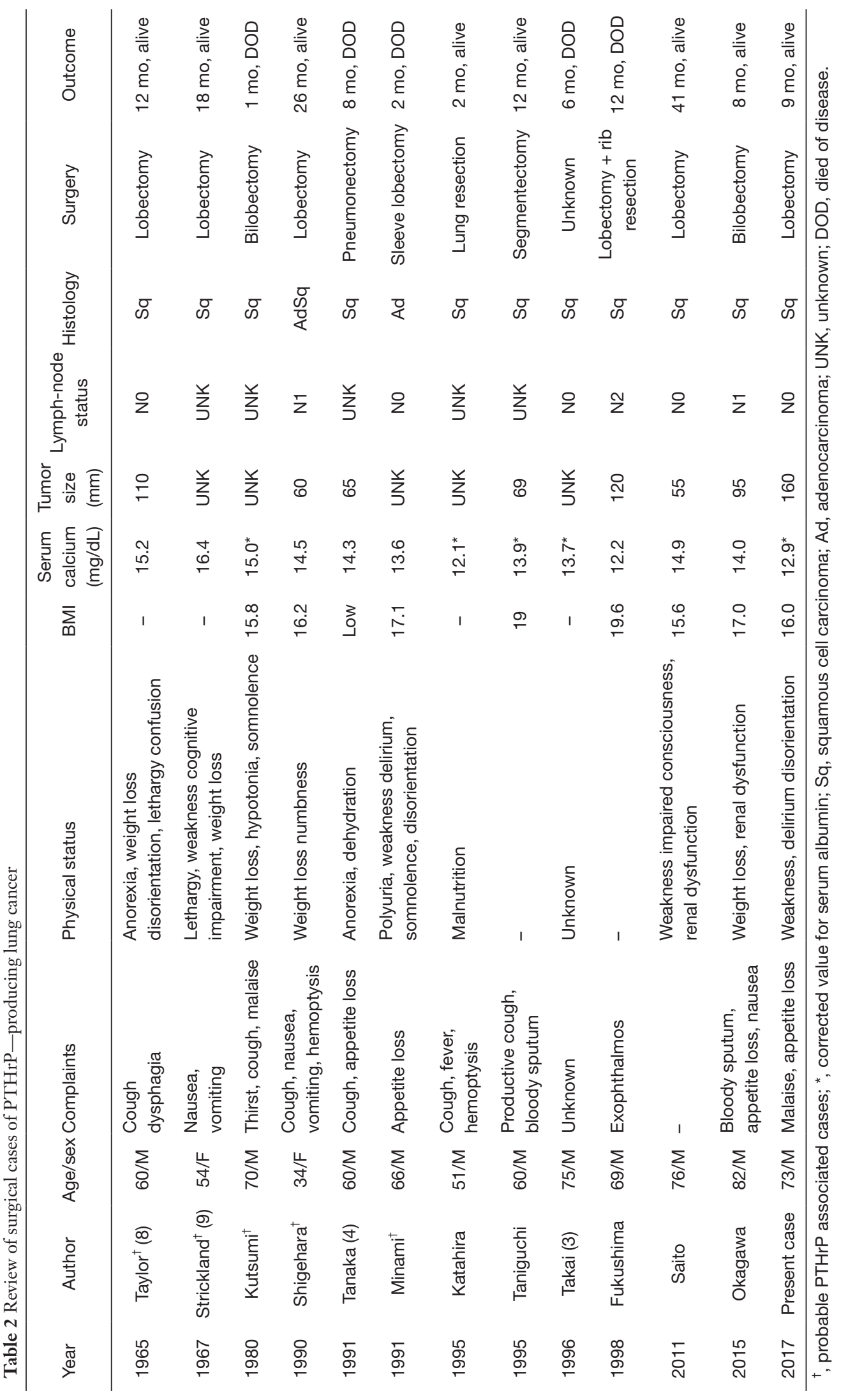


with HHM who have undergone complete resection of $\mathrm{PTHrP}$-associated lung cancer is longer than 12 months, in spite of these patients' poor condition. This may be because the PTHrP-induced hypercalcemia rapidly resolves postoperatively, and the patient's performance status improves early in the postoperative period. Although there is no established role of surgery for lung cancer or HHM in a palliative setting, patients with HHM may be considered candidates for palliative surgery. It is also possible that these patients' physical status may improve postoperatively, making adjuvant therapy an option.

Because this discussion is based on only a small number of previous reports, further studies should be performed to reach any definite conclusions. Hypercalcemia is associated with extremely poor median survival, but surgery in some cases may improve the patients' survival and quality of life.

\section{Conclusions}

Although hypercalcemia is associated with extremely poor survival, complete resection may improve survival and quality of life in patients with PTHrP-secreting lung cancer.

\section{Acknowledgements}

We thank Angela Morben, DVM, ELS, from Edanz Group (www.edanzediting.com/ac), for editing a draft of this manuscript.

\section{Footnote}

Conflicts of Interest: The authors have no conflicts of interest to declare.

Informed Consent: Written informed consent for the publication of this article was obtained from the patient.

\section{References}

1. Jameson JL, Longo DL. Chapter 121: Paraneoplastic Syndromes: Endocrinologic/Hematologic. In: Kasper D, Fauci A, Hauser S. editors. Harrison's Principles of Internal Medicine, 19e, 2015.

2. Iguchi H, Katakami H, Ichinose $Y$, et al. A case of squamous cell lung carcinoma with high concentration of parathyroid hormone-related peptide in serum and pleural effusion presenting hypercalcemia. Jpn J Cancer Res $1993 ; 84: 419-24$.
3. Takai E, Yano T, Iguchi H, et al. Tumor-induced hypercalcemia and parathyroid hormone-related protein in lung carcinoma. Cancer 1996;78:1384-7.

4. Tanaka H, Kobayashi S, Masaoka A, Honda S, Yamaguchi K. Hypercalcemia induced by parathyroid hormone-related protein from lung cancer tissue. Chest 1991;100:1451-3.

5. Mirrakhimov AE. Hypercalcemia of Malignancy: An Update on Pathogenesis and Management. N Am J Med Sci 2015;7:483-93.

6. Kanaji N, Watanabe N, Kita N, et al. Paraneoplastic syndromes associated with lung cancer. World J Clin Oncol 2014;5:197-223.

7. Pelosof LC, Gerber DE. Paraneoplastic syndromes: an approach to diagnosis and treatment. Mayo Clin Proc 2010;85:838-54.

8. Taylor DM, Siemsen AW. Bronchogenic carcinoma simulating hyperparathyroidism. Arch Intern Med 1965;115:67-73.

9. Strickland NJ, Bold AM, Medd WE. Bronchial carcinoma with hypercalcaemia simulating cerebral metastases. $\mathrm{Br}$ Med J 1967;3:590-2.

10. Suva LJ, Winslow GA, Wettenhall RE, et al. A parathyroid hormone-related protein implicated in malignant hypercalcemia: cloning and expression. Science 1987;237:893-6.

11. Insogna KL, Stewart AF, Morris CA, et al. Native and a synthetic analogue of the malignancy-associated parathyroid hormone-like protein have in vitro transforming growth factor-like properties. J Clin Invest 1989;83:1057-60.

12. Krouse RS, Nelson RA, Farrell BR, et al. Surgical palliation at a cancer center: incidence and outcomes. Arch Surg 2001;136:773-8.

13. Miner TJ, Brennan MF, Jaques DP. A prospective, symptom related, outcomes analysis of 1022 palliative procedures for advanced cancer. Ann Surg 2004;240:71926; discussion 726-7.

14. Miner TJ, Cohen J, Charpentier K, et al. The palliative triangle: improved patient selection and outcomes associated with palliative operations. Arch Surg 2011;146:517-22.

Cite this article as: Kamata $\mathrm{T}$, Koh E, Masunaga A, Okabayashi A, Hasegawa M, Katsura H, Hiroshima K, Sekine Y. A surgical case of lung cancer with poor general status associated with parathyroid hormone-related protein. J Thorac Dis 2018;10(5):E372-E377. doi: 10.21037/jtd.2018.04.96 